\title{
The Dorsomedial Hypothalamic Nucleus In Autonomic And Neuroendocrine Homeostasis
}

\author{
LEE L. BERNARDIS
}

\begin{abstract}
SUMMARY: Median eminence and ventromedial hypothalamus have in the past been the principal foci of research in neuroendocrine and neurovisceral control mechanisms. The present report provides an overview of work involving the dorsomedial hypothalamic nucleus (DMN). This structure is located dorsal to the ventromedial hypothalamic nucleus (VMN) and extends anteroposteriorly from the plane of the largest cross section of the VMN to the plane of the dorsal premammillary nucleus. Fibers from the DMN pass with the periventricular system and the dorsal longitudinal fasciculas of Schütz and have been traced to the midbrain tegmentum and reticular formation. Intrahypothalamic connections involve intensive networks between DMN, lateral hypothalamic nucleus (LHN) and VMN. Regarding neurotransmitters, recent studies indicate that the DMN receives noradrenergic innervation along two pathways, a
\end{abstract}

RÉSUMÉ: Dans le passé, l'éminence médiane et l'hypothalamus ventromédian ont le plus reçu l'attention des chercheurs. Le présent travail a pour but de faire une revue de nos connaissances au sujet du noyau hypothalamique dorsomedian (NDM), tant du point de vue anatomique (voies et fibres de connections) qu'histochimique (importance de linnervation dorsal and a ventral one. Monoaminecontaining systems approach the DMN from the lateral hypothalamus and the bulk of these fibers are carried in the medium forebrain bundle from their cells of origin in the brain stem. Studies of the vascular supply indicate that both VMN and $D M N$ receive their blood supply from the internal carotid artery. It has been recently demonstrated that the DMN is involved in the control of food intake and possibly water intake as well. Discrete lesions in the DMN have caused hypophagia and hypodipsia, and implantation of epinephrine and norepinephrine in this area has initiated eating. Many years ago, electrical stimulation of this area was reported to cause eating. Although DMN lesions cause hypodipsia, they do not result in the reduced waterlfood intake ratios that are so characteristic of the VMN syndrome. DMN lesions are also followed by re(Please turn to page 57)

catécholaminerigique), vasculaire et physiologique (démonstration récente du rôle du NDM dans le contrôle de l'apport calorique et liquidien; rôle dans le "resetting" du contrôle autunome central; dans le contrôle de la LTH et possiblement du facteur inhibiteur de l'hormone de croissance et enfin rôle important dans le contrôle de certains mécanismes neuroviscéraux).
Departments of Surgery and Pathology, State University of New York at Buffalo, Buffalo, New York 14215, U.S.A.

This review was written and some of the reported studies were conducted while the author was supported by General Medical Sciences Grant GM 15768, National Institutes of Health.

Reprint requests to Dr. L. L. Bernardis, State University of New York at Buffalo, 462 Grider St. Buffalo N.Y. 14215 U.S.A.

\section{INTRODUCTION}

The localization of diencephalic "centers" controlling both extrapituitary homeostatic functions (i.e. food and water intake) and neuroendocrine (i.e. hypothalamo-pituitary) relationships has revealed considerable functional specificity of fairly well-defined areas and fiber tracts. Thus, the medial hypothalamus has been implicated in satiety ("satiety center') and the lateral hypothalamus in feeding ("feeding center') (Anand and Brobeck, 1951). The supraoptic and paraventricular nuclei of the hypothalamus have been recognized as the formation sites of anti-diuretic hormone (Hild and Zetler, 1953) and of oxytocin (Olivecrona, 1957), and finally, the ventromedial hypothalamus has been demonstrated to be involved in the control of growth hormone $(\mathrm{GH})$ secretion (Bernardis and Frohman, 1967; Frohman and Bernardis, 1968).

The median eminence (ME) has been the principal focus of most investigators attention (for reviews see Knigge, Scott and Weindl, 1972; Martini, Motta and Fraschini, 1970; Nalbandov, 1963) since interference with its structural integrity invariably results in functional disruption of all adenohypophyseal hormone secretion. However, the concept that the hypophysiotrophic principles - releasing and inhibiting factors - are formed in the ME has been questioned (Mess, Fraschini, Motta and Martini, 1967) and the concept has been advanced that the $\mathrm{ME}$ is merely a stopover point from which the hypophysiotrophic principles formed in more distant areas of the hypothalamus are released into the primary portal plexus. Areas 
beyond the limits of the ME which exert hypophysiotrophic activity have been well demonstrated by the definition of the hypophysiotrophic area (HTA) by Halasz and his coworkers (Halasz, Pupp and Uhlarik, 1962).

For the aforementioned reasons the majority of neuroendocrine studies have been concentrated on the basal hypothalamus and the HTA, and little attention has been directed toward the dorsal neurons of the hypothalamus. In an attempt to correct this the present review addresses itself to the dorsomedial hypothalamus, in particular the dorsomedial hypothalamic nucleus $(D M N)$, and represents an attempt to integrate many as yet uncoordinated findings in many subdisciplines into a structural-functional Gestalt view of this diencephalic area.

\section{ANATOMY, HISTOLOGY}

The DMN are located dorsal to the ventromedial hypothalamic nuclei (VMN) and Krieg (1932) distinguishes two subdivisions, the nucleus dorsomedialis pars ventralis and pars dorsalis. The former borders on the VMN, separated by a cell-free zone, and is anteriorly and dorsally continued with the pars dorsalis of the nucleus. In its posterior aspect it is in contact with the nucleus posterior hypothalami. (Figure 1)

The fornix column and the commissura supraoptica dorsalis, pars dorsalis form the lateral borders. Axons have been described as passing dorsally with the periventricular axons into the periventricular fibers, the main bundle of which passes through the nucleus (Krieg, 1932). This original work has been confirmed by recent evidence which is summarized in Sutin's (1966) review. Periventricular fibers indeed pass from the ventral premamillary nucleus, posterior periventricular nucleus and the DMN and it is clear that powerful relations exist between the DMN and the periventricular system, which is probably its major outflow. It should also be noted that Showers (1958) has reported periventricular degeneration

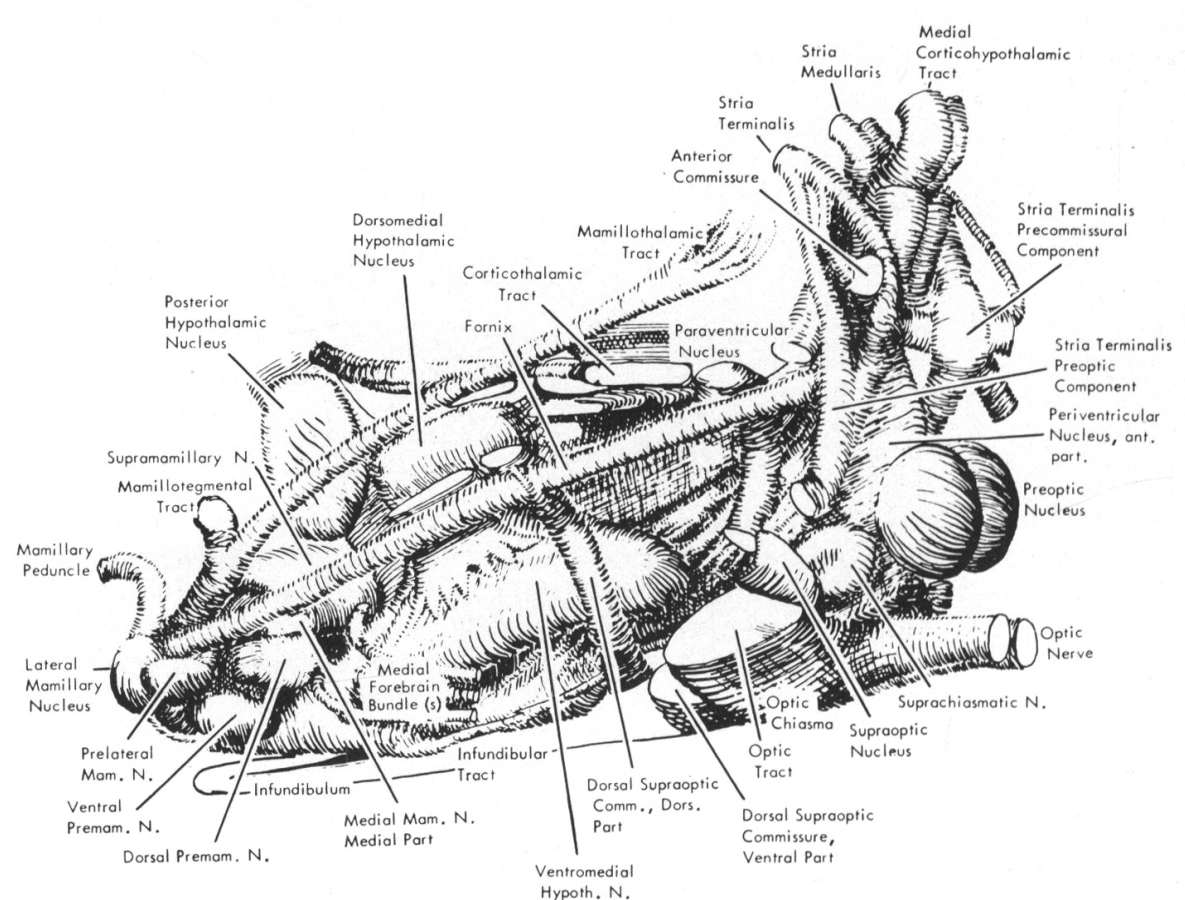

Figure I: View of the rat hypothalamus showing relationship of nuclei and fiber tracts. (Modified after Krieg, 1932).

to the VMN, DMN and LHN in her studies in monkeys with thalamic dorsomedial lesions.

The pars dorsalis . . " a poorly defined and inconspicuous cell group" . . . extends from the paraventricular nucleus to the medial margin of the zona incerta and nucleus reticularis thalami, along a line joining the mamillothalamic tract and the fornix (Krieg, 1932). Dorsally the pars dorsalis borders on the nucleus reuniens thalami and the nucleus centralis thalami while posteriorly it fuses with the pars ventralis of the DMN. The cells of this part of the DMN are indefinite in their connections and the axons pass probably with the periventricular fibers. The constituent cells of both pars ventralis and pars dorsalis are small but the cell nuclei of the pars ventralis are somewhat larger than those of the pars dorsalis (Krieg, 1932). Medially, the DMN borders on the ependyma of the third ventricle but its cells do not have the intimate contact as found in the arcuate nucleus.

\section{FIBER CONNECTIONS}

The nucleus dorsomedialis generally is considered as coming under the influence of fibers from the reticular zone of the thalamus. Fibers radiating from - and converging on - the area between the medial lemniscus and the cerebral peduncle turn dorsally as what Krieg (1932) has termed submamillothalamic fibers. Other fibers turn ventrally as commissura supraoptica dorsalis pars dorsalis (commissure of Ganser) and as the fasciculus hypothalamicus. By this term Krieg designated certain fibers which turn ventrally either ventral or dorsal to the fornix and do not decussate. He noted that they passed medially between the medial lemniscus and the medial forebrain bundle and became lost in the region of the VMN. He thought that they were intermingled with, but in general were caudal to, Ganser's commissure and noted that they probably synapsed in the VMN. Other fibers cross the midline as commissura interventralis thalami.

Krieg's (1932) description indicates that the fiber connections to and from the DMN were poorly understood at that time but he suspected that the axons of the DMN probably passed with periventricular fibers, together with fibers from the 
periventricular, suprachiasmatic, ventromedial, arcuate and posterior hypothalamic nuclei. Other efferent descending fibers have been reported to travel in the dorsal longitudinal fasciculus of Schütz (fasciculus longitudinalis dorsalis) and to extend caudalward to Gudden's dorsal segmental nucleus (Ariens Kappers, Huber and Crosby, 1960). The latter authors assumed a continuation of this system, after synapsing in that nucleus, to visceral motor cell groups in the brain stem. The fiber flow from the DMN through the periventricular system (Krieg, 1932) has been confirmed by recent findings. Millhouse (1969) has described that "path neurons" - so called because of their location in the pathway of the medial forebrain bundle (MFB, fasciculus medialis telencephali) - course with axons dorsomedially into the periventricular system. The latter, it should be recalled, is continuous with the dorsal longitudinal fasciculus of Schütz and represents a major efferent, descending hypothalamic pathway.

In a more recent description of the hypothalamic fiber system Ban (1964) indicated that ascending fibers to the DMN had been traced in the tracts coming from the mesencephalic gray, which also supply the paraventricular and posterior hypothalamic nuclei. Some descending fibers from both VMN and DMN have been traced contralaterally through the supramamillary decussation and terminate dorsal to the nucleus oculomotorius. Other descending fibers have been found to course through the dorsal part of the pedunculus mamillaris to the ventral part of the midbrain tegmentum.

The above findings have also been confirmed by Johnson (1965) who described degenerating fibers after DMN lesions as being traceable to the midbrain tegmentum through hypothalamo-tegmental tracts. Other degenerating fibers from the DMN were shown to course caudally to the midbrain tegmentum as the dorsal hypothalamo-tegmental tract and to terminate in the midbrain reticular formation, the nucleus mesencephalicus profundus pars dorsalis of the older literature. Similar findings were reported by Petrovicky (1967). Lesions in the DMN were followed by degeneration in the vicinity of the third ventricle and could be traced as far as the central gray of the midbrain and the nucleus centralis superior of Bechterew.

The DMN also receives fibers from a lateral direction, the field $\mathrm{H}_{2}$ of Forel (lenticular fasciculus), which passes over the fornix and thus reaches the DMN. These studies in the Macaque brain also showed that numerous single fibers and bundles of fibers pierce the border tracts between the lateral hypothalamic zone and the dorsomedial area (Smialowski, 1973).

Intrahypothalamic fiber connections involving the DMN have been studied by Guillery (1957), who found moderate fiber degeneration through the lateral hypothalamic nucleus and into the diagonal band of Broca following lesions in the DMN. He also noted that fibers from the zona incerta entered the lateral hypothalamic area. The latter connections will be discussed from a functional standpoint in the section on food intake. The findings of Matano, Sakai and Ban (1969) are also relevant. The Japanese workers noted that the DMN send dendrites into the lateral hypothalamic area, a finding that has been substantiated by Millhouse (1969) who found . . . "impressive co-mingling of dendrites between the lateral hypothalamus (path neurons) and the medial zone nuclei at this level, the ventromedial (HM) and dorsomedial (HD) hypothalamic nuclei."

Millhouse also noted that collaterals of path neurons at the level of the VMN arch over the VMN into the periventricular zone, and along their course there are additional collaterals which synapse with dendrites of both the VMN and DMN (Millhouse, 1969). This is particularly well shown in Figure 2.

Recently, Chi (1970) reported terminal degeneration in the DMN and dorsal hypothalamic area following LHN lesions, using the Fink-Heimer

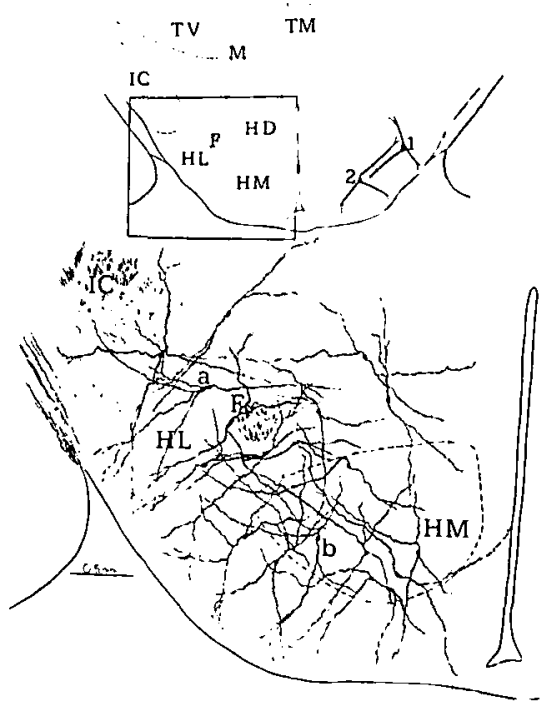

Figure 2: The MFB at the level of the ventromedial hypothalamic nucleus. Path neuron a, in lateral hypothalamus (HL), is typical of the neurons located along the MFB. Its wide ranging dendritic tree spreads out into the medial zone nuclei and internal capsule (IC) and extends nearly to the pial surface. Neurons in the ventromedial hypothalamus (HM) such as cell b, have dendrites reaching into $\mathrm{HL}$. As seen here (and schematically in the top illustration, cells 1 and 2), there is an impressive co-mingling of dendrites between lateral hypothalamus (path neurons) and the medial zone nuclei at this level, the ventro medial (HM) and the dorsomedial (HD) hypothalamic nuclei $M$, mammillothalamic tract; TM, midline thalamus; TV, ventral thalamus. Transverse section, 16 day rat, rapid Golgi methods. From Millhouse, 1969.

method. He noted that both the core of the VMN and the cell-poor zone surrounding it were free of degeneration and concluded that "the lateral hypothalamic projection to the dorsomedial hypothalamus does not seem to be continued to any significant extent by a link between the dorsomedial and ventromedial nuclei." Similarly, Eager, Chi and Wolf (1971) clearly demonstrated that degeneration after lateral hypothalamic lesions passes into the DMN. They also noted that their findings of a pathway from the lateral hypothalamus to the VMN, which reciprocates a previously postulated VMN-LHN pathway, (Arees and 
Mayer, 1967; Mayer and Arees, 1968) lends anatomical support to the concept that the VMN and LHN areas of the hypothalamus act as reciprocal centers in the control of feeding and possibly other motivated behavior. More recently, Eager, Chi and Wolf, (1971) have clearly shown that degeneration after lateral hypothalamic lesions passes into the DMN, and Chi (1970) has reported terminal degeneration in the DMN following LHN lesions, using the Fink-Heimer method, which allows the demonstration of degenerating axon terminals of fibers of a wide caliber range. Following lesions of the DMN he found a great deal of terminal degeneration in the VMN.

Some of the best Golgi studies of the areas under discussion can be found in Szentagothai, Flerko, Mess and Halasz' (1968) book. Particularly noteworthy are the sections in which dendrites are shown to extend from a single VMN cell onto dendrites and cells in the DMN and laterally into the LHN, indicating a very close link between these zones. The latter, as alluded to above, will enter into our discussion of the influence of the DMN on food intake control.

It has been known for some time that the amygdala connect with the VMN via the stria terminalis (Gloor, 1956; Raisman, 1970; Field, 1972). The DMN also receives its nervous supply from the stria. Heimer and Nauta (1969) have analyzed the terminal area of the stria which, as they state, is often described as a cellpoor zone. They found it contained a considerable number of neuronal perikarya. They noted a large number of dendrites radiating into this zone, mostly from the VMN, but also from the DMN and the arcuate nuclei.

\section{NEUROTRANSMITTERS}

Studies on the nature of the neurotransmitters subserving impulse transmission in the hypothalamus (Dahlström and Fuxe, 1964; Anden, Dahlström, Fuxe and Larsson, 1965; Fuxe, 1965) have demonstrated that momoaminecontaining ascending pathways arise from groups of cells located primar- ily in the ventro-lateral reticular formation, the ventral part of the midline raphe and the lateral part of the periventricular and central gray matter. In addition, Fuxe (1965) has found three small groups of catecholamine-containing cells in or near the hypothalamus. One of these lies dorsal to and in the DMN which, together with the external layer of the $\mathrm{ME}$, contains very high concentrations of dopamine. In all regions of the rat brain where monoaminecontaining cells have been described, they can be visualized in thiocholine-stained material that contains small amounts of True Cholinesterase (AChE). Possibly, these neurons are cholinoceptive.

More recently, Jonsson, Fuxe and Hökffelt (1972) have performed deafferentation studies in rats and found that complete deafferentation produced an almost complete disappearance of catecholaminecontaining nerve terminals in all parts of the hypothalamic island, except the ME. This island, among other structures, included the DMN. No depletion was found in the external layer of the ME. The authors concluded that the hypothalamic noradrenergic innervation arises mainly along two pathways: one pathway probably enters dorsally and sends fibers medially into the dorsal part of the hypothalamus, innervating the DMN and the paraventricular nuclei. The other pathway runs ventrally and sends fibers medially along the ventral surface of the brain to innervate the VMN and also probably the internal layer of the ME and part of the periventricular system. It may be deduced from these findings that the DMN receive a dual output: from the firstmentioned, direct pathway and also from the second, periventricular system-related pathway. The latter, it will be recalled, is likely involved in impulse transmission from the DMN (Gurdjian, 1927; Krieg, 1932).

The origin of monoaminecontaining fibers in the rat has recently been studied by Smith and Fink (1972). Lesions involving the VMN, DMN and the paraventricular nuclei were followed by a marked accumulation of fluorescence in the lateral hypothalamic area, indicating the likely direction from which monoamine-containing systems approach these regions. The identification of the lateral hypothalamic area as a region from which such fibers approach the medial hypothalamus supports studies (Anden, Dahlström, Fuxe, Larsson, Ohlsen and Ungerstedt, 1966) which demonstrate that the medial forebrain bundle carries the bulk of monoaminecontaining fibers from their cell bodies in the brain stem to the diencephalon.

The hypothalamus in general and the DMN in particular have also been shown to contain cholinergic fibers. One of the two cholinesterase-containing pathways (AChE) in the rat forebrain was found by Shute and Lewis (1963) to arise from the substantia nigra and ventral tegmental area of the midbrain and to travel through the hypothalamus and subthalamus enroute to the basal forebrain area. This pathway contains only AChE. Their axons can be traced rostrally to the globus pallidus and the ventral part of the reticular thalamic nucleus. Not only AChE-containing cells, but also fibers of passage can be seen in most of the dorsal hypothalamic areas. These data suggest a strong involvement of both catecholamines, i.e. dopamine, and of acetylcholine as transmitters in and to the DMN.

\section{VASCULAR SUPPLY, EPENDYMAL CONNECTIONS}

Recent findings have suggested that the hypothalamic neurons convey their hypophysiotrophic principles not directly into the primary plexus of the portal system in the $\mathrm{ME}$, but rather via the cerebral spinal fluid in the third ventricle. From there, the releasing and inhibiting factors reach the primary portal plexus and thence the adenohypophyseal parenchyma. This view has been strongly supported by Knigge's findings and has been well reviewed (Knigge, Scott and Weindl, 1972). The transport involves a special type of ependymal cells, the tanycytes (Horstmann, 


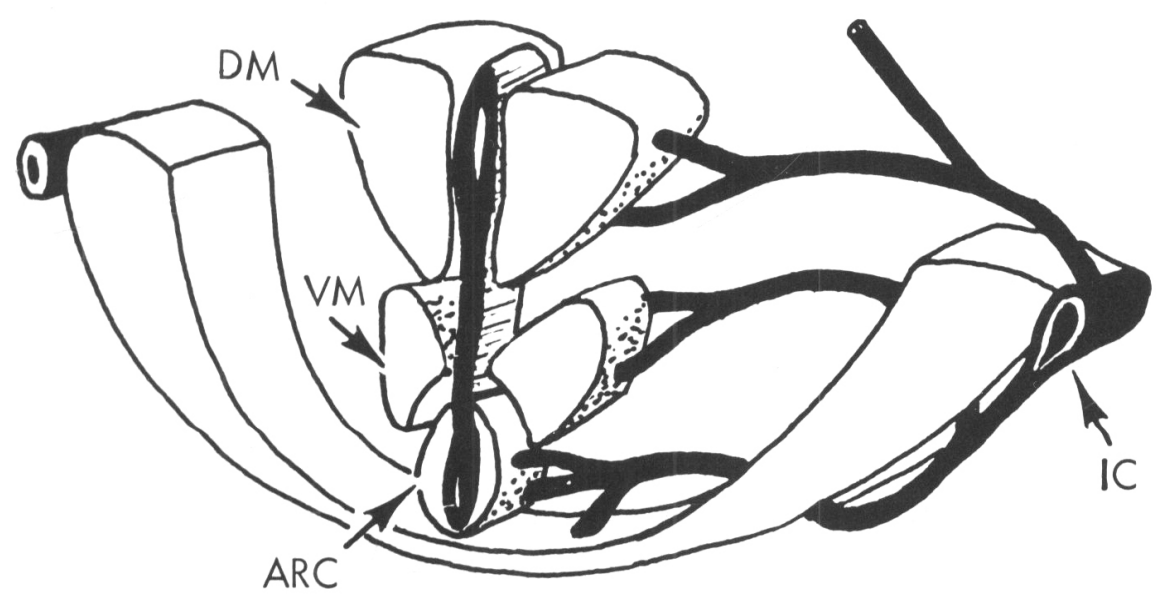

Figure 3: Vascular supply of the dorsomedial (DM) and ventromedial (VM) hypothalamic nuclei (DM) dorsomedial nucleus, (VM) ventromedial nucleus, (ARC) arcuate nucleus and (IC) internal carotid artery. Modified after Scremin, 1970.

1954). These cells leave the soma in the ependymal lining and penetrate well into the neuropil, differing structurally and chemically from the more familiar cuboidal-columnar ependymal lining cells. Millhouse (1971) has recently also shown that, proceeding from the dorsal wall to the ventral aspect of the third ventricular wall, the density of the tanycytes appears to be greater. Thus, the distribution of these specialized cells is different for the area in the dorsomedial and the ventromedial hypothalamic nuclei.

The vascular supply of the DMN has been well described in a recent study by Scremin (1970). Fig. 3 . Principally, the hypothalamus in the rat is supplied by vessels originating in the internal carotid, the posterior communicating and the cerebral arteries, the veins showing a similar distrubution.

The author raises an important point: the effects of experimental lesions in the hypothalamus have been assumed to be due to the loss of nerve cells and nerve fibers within the area of the lesion. Based on his data in the rat's hypothalamus, Scremin points out that "the possibility of the involvement of areas distant to the primary lesion by the destruction of blood vessels crossing through the lesioned area has not been discussed so far in the papers dealing with hypothalamic lesions". Thus, disturbances of neuroendoc- rine and autonomic nature could be provoked in areas away from the principal lesion site by suppressing their vascular supply. Areas falling into this category are the supraoptic nucleus, the anterior dorsolateral hypothalamus and the posterior dorsolateral hypothalamus lateral to the DMN and VMN. It appears then that the VMN and DMN are not affected by lesions at different sites around them.

\section{FOOD INTAKE}

The "classical" hypothalamic areas involved in food intake control have been characterized as the ventromedial "satiety center" and the lateral hypothalamic "feeding center.' (Anand and Brobeck, 1951). However, evidence implicating more dorsal and medial hypothalamic structures which was published in the early forties by the Hess group in Zürich (Brügger, 1943) is seldom referred to. Ten years before Delgado and Anand (1953) reported that electrical stimulation of the lateral hypothalamic area induced feeding in the cat, Brügger (1943) obtained "ausgesprochene Fressgier" - a voracious drive to eat - also in the cat, following electrical stimulation of the area between the fornix and the mamillothalamic tract, corresponding to the DMN area.

In an excellent review, Akert (1961) pointed out that the medial and lateral hypothalamic loci de- scribed by Brügger influence food intake differently from the classical lateral area, and that more significance should be attached to the mediodorsal rather than the lateral hypothalamic area.

Recognizing the discrepancy between the two localizations, Larsson (1954) reinvestigated the problem, using the unanesthetized sheep and goat as the experimental animals. Hyperphagia was induced by stimulation in the area of the DMN, and it was mostly limited to the period of stimulation. Delgado and Anand's animals, on the other hand, did not increase food intake until the second postoperative day. The latter authors indicate that the lateral hypothalamic area stimulated in their experiments is crossed by the medial forebrain bundle and fuses caudally with the zona incerta and substantia nigra. The former, it will be recalled, sends fibers into the lateral hypothalamic area and borders on the DMN pars dorsalis (Guillery, 1957; Matano, Sakai and Ban, 1969).

Recent studies in the rat on the effect of the DMN on the control of

Figure 4: Food intake (hyperphagia, bulimia), elicited by electrical stimulation of the dorsal intermediate hypothalamus (Horsley-Clarke coordinates: $\mathrm{F}+10.0, \mathrm{H}-4.0, \mathrm{ML} 1.5$ to 2.0). Sagittal section, about $1.5 \mathrm{~mm}$ from the midline. The active area (solid circles) is situated between the fornix and the mammillothalamic tract, somewhat closer to the latter. (AC) anterior commissure, (F) fornix, (TM) tract of Meynert, (CM) mammallary body, (VM) ventromedial nucleus, (MT) mammallothalamic tract (MI) massa intermedia, (TO) optic tract. (From Brügger, 1943, redrawn, Akert, 1961).

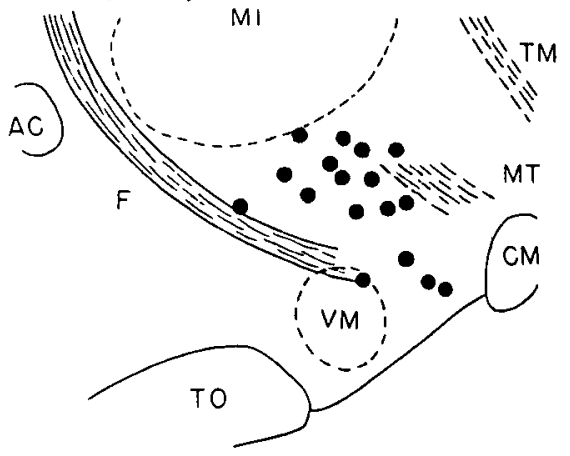


food intake have yielded results in keeping with the stimulation studies of Brügger (1943) and Larsson (1954). Electrolytic lesions primarily destroying the DMN, but impinging on the posterior hypothalamus as well, resulted consistently in hypophagia and hypodipsia. This was first noted in the weanling female rat (Bernardis, Box and Stevenson, 1963) and was subsequently studied in more detail in both weanling and adult rats of both sexes. (Bernardis, 1970; Bernardis and Frohman, 1971; Bernardis, 1972a; Bernardis, 1972b).

It is worth recalling that some studies have suggested a sex difference in food intake following ventromedial hypothalamic manipulation (Valenstein, Cox and Kakolewski, 1969). It has been noted that hypophagia and reduced weight gain occur in both sexes after DMN lesions (weanling - Bernardis 1970, 1972b mature - Bernardis, 1972a).

Studies in the author's laboratory have also shown that DMN lesions disrupt the normal diurnal feeding and weight gain pattern in weanling rats. The DMN rats showed their usual hypophagia but distributed their feeding over both dark and light periods of the day. Similar findings were made for the weanling VMNlesioned rat, thus demonstrating that the area subserving "cycling" of feeding and weight gain is rather large and covers both VMN and DMN and perhaps goes beyond these hypothalamic loci.

The fact that the classical localization studies on the feeding loci in the hypothalamus found the DMN to be a silent area (Anand and Brobeck, 1951) appears disturbing and might necessitate a reinterpretation. The principal questions arising from the new findings are: 1) does an area thus far unresponsive to manipulation by lesioning technique exert the described hypophagic effect on its own, i.e. independent of lateral hypothalamic area involvement, or 2) does the DMN syndrome represent an attenuated, lateral hypothalamic syndrome? Consideration of the circuitry in this part of the
TABLE 1

\begin{tabular}{|c|c|c|c|}
\hline Parameter & Group 1 & Group 2 & Group 3 \\
\hline Treatment* & VMNL & DMNL & $\mathrm{CON}$ \\
\hline $\mathrm{N}$ & 9 & 7 & 8 \\
\hline $\begin{array}{l}\text { Body weight } \\
\text { change }(\mathrm{GM})\end{array}$ & $152 \pm 10$ & $68 \pm 15 * * * *$ & $115 \pm 2$ \\
\hline $\begin{array}{l}\text { Body length } \\
\text { change }(\mathrm{MM})\end{array}$ & $82 \pm 7$ & $64 \pm 8$ & $107 \pm 3$ \\
\hline $\begin{array}{l}\text { Total food** } \\
\text { intake (Days 1-30) }\end{array}$ & $23 \pm 1.1$ & $11 \pm 1.7^{* * * *}$ & $19 \pm 0.4$ \\
\hline $\begin{array}{l}\text { Food intake } \\
\text { (Days } 1-6)\end{array}$ & $14 \pm 1.7$ & $6 \pm 1.6^{* * *}$ & $18 \pm 0.8$ \\
\hline $\begin{array}{l}\text { Food intake } \\
\text { (Days 24-30) }\end{array}$ & $22 \pm 1.8$ & $11 \quad 1.8^{* * *}$ & $19 \pm 1.2$ \\
\hline $\begin{array}{l}\text { Total water } \\
\text { intake (Days 1-30) }\end{array}$ & $30 \pm 1.9$ & $16 \pm 2.4^{* * * *}$ & $33 \pm 1.7$ \\
\hline $\begin{array}{l}\text { Water intake } \\
\text { (Days } 1-6 \text { ) }\end{array}$ & $21 \pm 3.9$ & $9 \pm 1.2^{* *}$ & $28 \pm 1.2$ \\
\hline $\begin{array}{l}\text { Water intake } \\
\text { (Days 24-30) }\end{array}$ & $28 \pm 4.6$ & ${\underline{15 \pm 3.3^{*}}}^{*}$ & $34 \pm 1.9$ \\
\hline $\begin{array}{l}\text { Total water/Total } \\
\text { Food intake ratio }\end{array}$ & $1.31 \pm 0.08$ & $1.45 \pm 0.12$ & $1.69 \pm 0.09$ \\
\hline $\begin{array}{l}\text { Carcass fat } \\
(\% \text { Wet body weight })\end{array}$ & $35 \pm 3.5$ & $12 \pm 2.5 * * * *$ & $12 \pm 0.1$ \\
\hline $\begin{array}{l}\text { Carcass water } \\
\text { (\% Wet body weight) }\end{array}$ & $47 \pm 2.7$ & $65 \pm 1.7 * * * *$ & $64 \pm 0.3$ \\
\hline $\begin{array}{l}\text { Lean body mass } \\
\text { (\% Wet body weight) }\end{array}$ & $18 \pm 0.8$ & $23 \pm 0.7 * * * *$ & $24 \pm 0.2$ \\
\hline $\begin{array}{l}\text { Total food intake/Lean } \\
\text { body mass }\end{array}$ & $1.33 \pm 0.12$ & $0.50 \pm 0.02 * * * *$ & $0.82 \pm 0.02$ \\
\hline $\begin{array}{l}\text { Lean body mass/Food } \\
\text { intake }\end{array}$ & $\underline{0.80 \pm 0.07}$ & $2.44 \pm 0.42 * * *$ & $1.22 \pm 0.03$ \\
\hline
\end{tabular}

Table 1: The table juxtaposes data on food and water intake, ponderal and linear growth, and body composition in rats with ventromedial and dorsomedial hypothalamic lesions and sham-operated controls.

* VMNL - lesions in the ventromedial hypothalamic nuclei

DMNL - lesions in the dorsomedial hypothalamic nuclei

CON - sham-operated controls

** All food and water intake data are presented in $\mathrm{gm} /$ day

*** Mear \pm S.E.M.

Comparisons between Groups 1 and 2, respectively, and Group 3:

\begin{tabular}{l}
$\mathrm{p} \quad 0.05$ \\
$\frac{p}{\mathbf{p}}-0.02$ \\
$\frac{\mathbf{0}}{\mathrm{p}}-\overline{01} \overline{0.001}$ \\
\hline Comparisons between Groups 1 and 2 \\
$\mathrm{p}<0.05^{*}$ \\
$\mathrm{p}<0.02^{* *}$ \\
$\mathrm{p}<0.01^{* * *}$ \\
$\mathrm{p}<0.001^{* * * *}$ From Bernardis, 1970.
\end{tabular}

hypothalamus suggests that DMN lesions, in addition to destroying the DMN proper, injure neuronal circuits originating in the DMN and terminating in the lateral hypothalamic area. It should be re- called that Guillery (1957) has reported fiber degeneration after DMN lesions through the lateral hypothalamic area and into the diagonal band of Broca, and that zona incerta fibers enter the lateral 


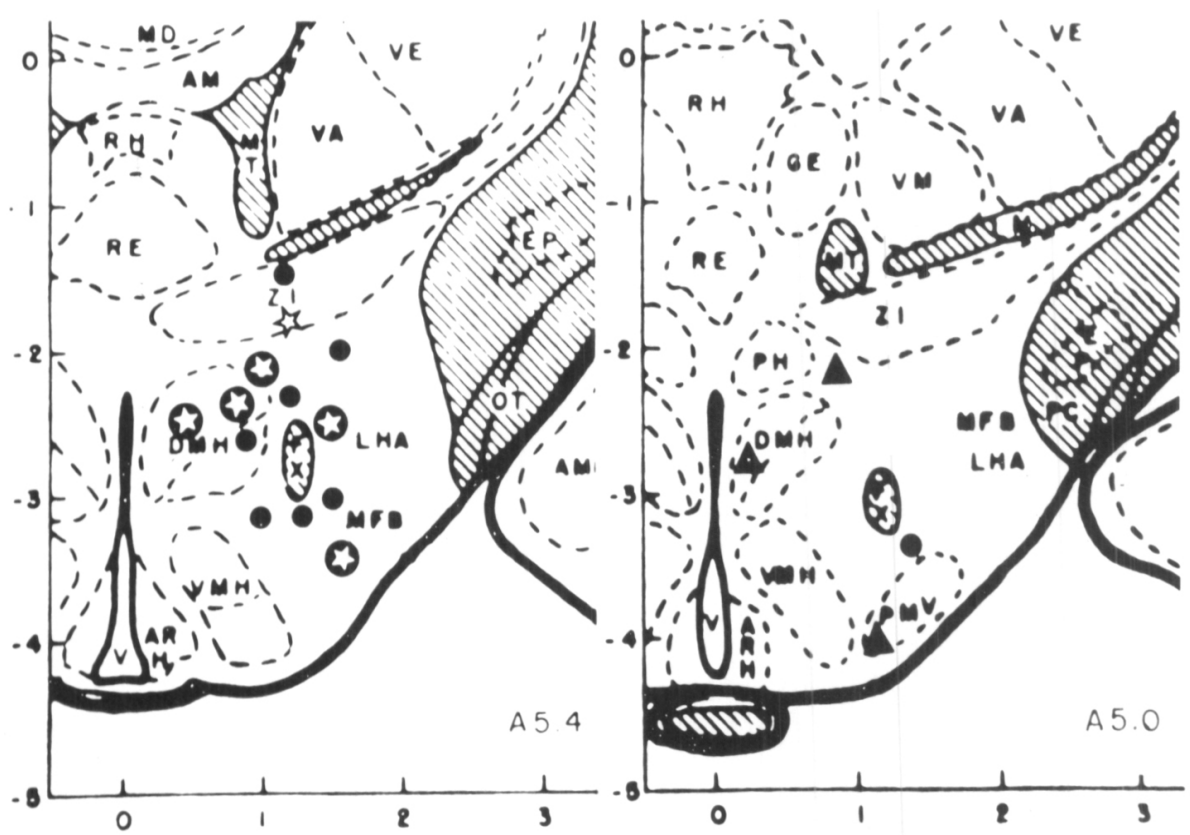

Figure 5: Localization of implant placements against the background of the DeGroot (1959) coordinate system of the rat brain. Filled circles indicate consistently good effects of both adrenergic and cholinergic stimulation, white stars inside filled circles indicate consistently excellent effects of both adrenergic and cholinergic effects; black stars represent predominantly adrenergic placements. Black triangles indicate negative placements. (V) third ventricle, (ARH) arcuate nucleus, (VMH) ventromedial nucleus, (MFB) medial forebrain bundle, (LHA) lateral hypothalamic area, (DMN) dorsomedial hypothalamic nucleus, (OT) optic tract, (ZI) zona incerta, (RE) nucleus reuniens thalamic, (RH) thalamic rhomboideus nucleus, (MD) thalamic mediodorsal nucleus, (AM) thalamic anteromedial nucleus, (VA) thalamic ventral nucleus pars anterior, (VE) ventral thálamic nucleus, (MT) mammillothalamic tract, (EP) entopeduncular nucleus, (GE) thalamic gelatinosus nucleus, (PH) posterior hypothalamic nucleus, (VM) ventral thalamic nucleus, pars medialis, (PC) cerebral peduncle, (PMV) ventral premamillary nucleus, (LM) medial lemniscus. From Grossman, 1962.

hypothalamic area. Undoubtedly, the zona incerta is also injured by even precisely placed DMN lesions. This might explain why, following DMN injury, food intake is profoundly decreased but not entirely abolished. The latter change, aphagia, is a consequence of the lateral hypothalamic syndrome. (Anand and Brobeck, 1951; Bernardis and Frohman, 1970; Teitelbaum and Epstein, 1962).

The Bernardis data are also reconcilable with the findings by Grossman (1962) in which he demonstrated that placement of epinephrine and norepinephrine in an area between the fornix and the mamillothalamic tract - the "Brügger area" - and lateral and dorsal to the VMN induced feeding in satiated rats.Implantation of critical analysis of the fiber tracts that involve the DMN and its immediate neuronal neighbors, principally the VMN and the lateral hypothalamic nuclei, and the possible interrelationship between the DMN and both the lateral hypothalamic area and the zona incerta (Gurdjian, 1927; Krieg, 1932; Ariens Kappers, Huber and Corsby, 1936; Guillery, 1957; Ban, 1964; Arees and Mayer, 1967; Mayer and Arees, 1968; Szentagothai, Flerko, Mess and Halasz, 1968; Heimer and Nauta, 1969; Millhouse, 1969; Christ, 1969). Nevertheless, the possibility cannot be excluded that connections between the VMN and DMN might play a role in normal food intake and in the hypophagia that follows DMN lesions. These connections appear to play a role in the relationship between the VMN and the lateral hypothalamic area on one hand and the DMN and the lateral hypothalamic area on the other (Arees and Mayer, 1967; Mayer and Arees, 1968) (See also Eager, 1971 and Chi, 1970; Chi and Wolf, 1971). Perhaps the most important papers relevant to the organization of the medial hypothalamus have been published recently by Millhouse (1973a, 1973b). Resting on evidence obtained by Golgi studies, they relate well with the 1969 paper on the lateral hypothalamus and show the various interdigitations of synaptic processes between lateral, ventromedial, periventricular and dorsomedial hypothalamic zones. The studies indicate that VMN dendrites are long and branch infrequently, and that the dendritic trees of the VMN cells do not show a particular orientation. The trees of a single neuron stretch out across the dorsoventral and mediolateral aspect of the VMN, and many of the dendrites protruding through and beyond the capsule of the VMN can be followed into the lateral hypothalamus, the $\mathrm{DMN}$, and to the ventral pial surface. Medial axons from both VMN and DMN extend into the ventral and perhaps dorsal lateral hypothalamic area. From Millhouse's latest study there is no direct evidence that medial axons 
actually synapse on lateral hypothalamic neurons.

The interrelationship between the DMN and the lateral hypothalamic area and between the DMN and the VMN in mature rats alluded to above is of interest in the light of DeGroot's findings (1967). He has reported that placement of VMN lesions followed by lateral hypothalamic lesions resulted in reduced food intake and weight gain. When the lateral hypothalamic lesions were placed prior to the VMN lesions, both food intake and weight gain remained low (1967). Recent experiments in weanling rats bearing double lesions show that DMN lesions had an attenuating effect on food intake and weight gain only when they had been placed prior to the VMN lesions. (Bernardis, Chlouverakis, Schnatz and Frohman, 1974). The latter data also show that destruction of the lateral hypothalamic feeding neurons has consequences different from those following $\mathrm{DMN}$ lesions and this might also be taken as pointing to a different functional capacity.

\section{WATER INTAKE}

Consumatory behavior is not only affected by DMN lesions in terms of reduced food intake but also water intake (Bernardis, 1970). It is of interest, however, that the DMN lesions do not cause a reduced water/food intake ratio, a change that is characteristic of the VMN syndrome (weanling rat - Bernardis, 1970; Bernardis and Frohman, 1971; Bernardis, 1972b; mature rat - Montemurro and Stevenson, 1957). It is also worth noting that DMN lesioned rats show normal carcass water content (Bernardis, 1970) and that both male and female mature DMN rats excrete a given water load at the same rate as appropriately sham-operated controls (Bernardis, 1972a). These findings are in contrast to the data reported by Montemurro and Stevenson (1957) who located an area in the rat lateral hypothalamus, the destruction of which causes adipsia and hypodipsia but is different from the lateral hypothalamic "feeding center' (Anand and Brobeck, 1951).
To this must be added the data by Grossman (1962) on the initiation of drinking in satiated rats by the implantation of cholinergic substances into the DMN. As with food intake, the question must be asked as to whether the observed effect on water intake might not be related to injury to connecting and interdigitating circuits of the "thirst center" in the lateral hypothalamic area and its related neurons. It is especially noteworthy that Millhouse has recently stated (1973b) that "the axons of the dorsomedial hypothalamic nucleus might be significant in integrating eating and drinking behavior."

\section{LOCOMOTOR ACTIVITY}

The extensive analyses by Richter (1927, 1952, 1967) of biological rhythms and spontaneous activity patterns have shown that a wide variety of endocrine manipulations including hypophysectomy fail to affect the "24-hour clock" in the rat. Using changes in running-wheel activity as criterion, he noted that . . . "the clock possibly is located somewhere in the hypothalamus." Indeed, Brooks (1946) demonstrated that the hypothalamic area in question might be the VMN, since lesions in this area in mature rats brought about a state of hypoactivity. In combination with hyperphagia, it might contribute to the profound obesity in this type of experimental animal. Bernardis (1972c) confirmed hypoactivity following VMN lesions in the weanling rat which, it should be recalled, is normophagic with normal weight gain but increased carcass fat (Bernardis and Frohman, 1967; Bernardis, 1970; Bernardis and Frohman,; 1970; Bernardis and Frohman, 1971; Bernardis, 1972c; Bernardis, 1973a; Bernardis, 1973b).

While in the intact rat decreased food intake or fasting is followed by hyperactivity (Slonaker, 1925; Wald and Jackson, 1944; Campbell and Sheffield, 1953; Stevenson and Rixon, 1957), the (hypophagic) weanling as well as mature DMN rat displays hypoactivity, which is accompanied by decreased body weight gain but normal body com- position (Bernardis, Box and Stevenson, 1963; Bernardis, 1970; Bernardis and Frohman, 1970; Bernardis, 1972a; Bernardis, 1972b). Unless DMN lesions affect food intake and activity simultaneously it could be speculated that the latter is an adjustment to the former to spare calories for anabolic processes.

Hypoactivity has also been described after the destruction of medial and lateral hypothalamic areas by lesions larger than the ones in the Bernardis studies (Gladfelter and Brobeck, 1962). However, destruction of the mamillothalamic tract, the medial forebrain bundle, the fornix and the periventricular area elsewhere in the hypothalamus did not cause a decrease in locomotor activity. The authors suggested that impulses from these areas leave the hypothalamus either by a very diffuse pathway, or by a dorsal or lateral route. It is conceivable that the lesions in the Bernardis studies interrupted dorsal pathways efferent from Gladfelter's and Brobeck's area(s) (1962) rather than destroying a primary "activity center." These authors emphasized that activity changes in their animals occurred independently of food and water intake; the opposite is true for the DMN lesioned rat.

\section{HYPOTHALAMO-PITUITARY RELATIONSHIPS}

As mentioned in the introductory section of this review, most studies addressing themselves to an exploration of hypothalamic sites involved in the control of the adenohypophysis have been confined to the basal hypothalamus, specifically the ME. Although Halasz' work has pointed to a wider involvement of hypothalamic structures than merely the ME, the Hypophysiotrophic Area (HTA) by definition does not include the DMN (Halasz, Pupp and Uhlarik, 1962).

Within the last few years, evidence has accumulated that the DMN is involved in hypophysiotrophic function. Lesion studies have suggested that the DMN might be involved in the control of prolactin (LTH) secretion. After destruction of an area involving the VMN, DMN 
TABLE 2

\begin{tabular}{|c|c|c|c|c|c|c|}
\hline Parameter & $\begin{array}{l}\text { Group } 1 \\
\text { VMNL }(25)^{*}\end{array}$ & $\begin{array}{l}\text { Group } 2 \\
\text { DMNL (7) }\end{array}$ & $\begin{array}{l}\text { Group } 3 \\
\text { SCON (S) }\end{array}$ & 1 vs 2 & $\begin{array}{l}\text { P } \\
1 \text { vs } 3\end{array}$ & 2 vs 3 \\
\hline Plasma GH $(\mu \mathrm{g} / \mathrm{ml})$ & $35.2 \neq 5.4 * *$ & $91.6 \stackrel{1}{\neq} 24.4$ & $77.8 \doteq 14.9$ & 0.01 & 0.01 & $\mathrm{~ns} * * *$ \\
\hline$\Delta$ Body Weight (gm) & $137 \stackrel{+}{*} 8$ & $68 \stackrel{1}{\stackrel{1}{*} 15}$ & $115 \nRightarrow 2$ & 0.001 & ns & 0.01 \\
\hline$\Delta$ Body Length $(\mathrm{mm})$ & $77 \stackrel{+}{=} 3$ & $64 \frac{1}{\bar{T}} 8$ & $107 \stackrel{ \pm}{=}$ & ns & 0.001 & 0.001 \\
\hline Food Intake (gm/day) & $20.4 \doteq 1.0$ & $11.3 \neq 1.7$ & $19.4 \stackrel{1}{=} 0.4$ & 0.001 & & 0.001 \\
\hline Carcass Fat (\% dry wt.) & $60 \neq 2$ & $32 \doteq 5$ & 374 & 0.001 & 0.001 & ns \\
\hline Strain: & Holtzman & \multicolumn{5}{|c|}{$\begin{array}{l}\text { *VMNL - lesions in the ventromedial } \\
\text { hypothalamic nuclei }\end{array}$} \\
\hline Age at operation: & 28 days & \multicolumn{5}{|c|}{$\begin{array}{l}\text { DMNL - lesions in the dorsomedial hypo- } \\
\text { thalamic nuclei }\end{array}$} \\
\hline $\begin{array}{l}\text { Duration of } \\
\text { experiment: }\end{array}$ & 31 days & \multicolumn{5}{|c|}{ SCON - sham-operated controls } \\
\hline Time of year: & Nov.-Dec. & \multicolumn{5}{|c|}{ ( ) population } \\
\hline Lesion current: & $1.0 \mathrm{mAmp}$ & \multicolumn{5}{|c|}{$* *$ Mean S.E.M. } \\
\hline Lesion time: & $12.5 \mathrm{sec}$. & \multicolumn{5}{|c|}{ *** statistically not significant } \\
\hline
\end{tabular}

Table 2: Plasma Growth Hormone (GH) levels and somatic parameters in rats with lesions in the ventromedial and dorsomedial hypothalamic nuclei, respectively, and of sham-operated controls. From Bernardis, 1973.

and the arcuate nuclei, prolonged diestrus and active corpora lutea were observed in the rat (Nikitovitch-Winer, 1970). Subsequent studies by Everett and Quinn (1966) showed that the mechanism(s) initiating and maintaining pseudopregnancy in rats is (are) easily distinguished from the mechanism(s) controlling ovulation. Pseudopregnancy was precipitated by stimulation of . . . "sites near the dorsomedial nucleus ..." - a sign of LTH secretion - and did not induce ovulation. The latter was brought about by stimulation of the preoptic area which failed to induce pseudopregnancy. This differential response provided further evidence for the existence of two separate hypothalamic mechanisms that can be selectively stimulated and in turn activate cells in the HTA to produce Prolactin Inhibiting Factor (PIF) and Luteinizing Hormone Releasing Factor (LHRF).

The DMN was also implicated in the pseudopregnancy - LTH control scheme by data from cervical stimulation experiments. Kawakami and Ibuki (1972) stimulated the cervix of mature rats on the day of estrus to induce pseudopregnancy and found an increase in multiple unit activity (MUA) in the anterior hypothalamic area and the DMN for several hours. The MUA of the ar- cuate nucleus decreased. From the fourth day of pseudopregnancy MUA decreased in the DMN, the anterior hypothalamic area and the hippocampus.

While the VMN has been implicated in the control of growth and Growth Hormone (GH) secretion (Hetherington and Ranson, 1942; Reichlin, 1961; Smith, 1927), proof for the participation of a specific area, i.e. the VMN, has been forthcoming only recently. Bernardis and Frohman (1967) were the first to report that destruction of the VMN without injury to the ME brought about a decrease of both pituitary and plasma GH levels. Subsequent lesion (Frohman and Bernardis, 1968; Bernardis and Frohman, 1970) and stimulation (Toivola and Gale, 1973) studies have confirmed these original findings and moved the VMN into the focal point of $\mathrm{GH}$ control.

Indications that the VMN may not be the sole hypothalamic locus involved in GH dynamics appeared in the early sixties, when it was reported that profound growth reduction occurred when weanling rats received electrolytic lesions in the DMN (Bernardis, Box and Stevenson, 1963). A recent re-investigation of this problem confirmed the original report. DMN lesions that do not injure the VMN are followed by pro- found reductions in both ponderal and linear growth but normal body composition (Bernardis, 1970; Bernardis and Frohman, 1970; Bernardis and Frohman, 1971). Follow-up studies revealed normal plasma glucose and insulin (Bernardis and Frohman, 1970, 1971) and triglyceride and cholesterol levels (Bernardis and Schnatz, 1970). One of the most remarkable features of this syndrome is the fact that plasma GH levels are normal or slightly elevated (Bernardis, 1973).

Oxygen consumption, thyroid and testes weights were normal, but adrenal weights were smaller in the DMN lesioned rats (Bernardis, 1972a, 1972b). Changes in the secretions of these glands have not been reported following DMN lesions, but evidence to be discussed indicates it is unlikely that the growth retardation in the DMN rat is due to deficiencies in the secretions of the above glands. Rather, it was proposed (Bernardis, 1972a, 1972b; Bernardis and Goldman, 1972) that the growth reduction is due to decreased food intake. Normal or even elevated GH levels cannot bring about normal growth under this condition.

Most recent studies by Nakayama et al (Nakayama, Tseng and Bernardis, 1973; Nakayama, Bernardis and Tseng, 1974), however, have shown that the DMN are involved in GH dynamics. Using an ultrastructuralquantitative approach the authors suggested that the DMN might be involved in the control of Growth Hormone Inhibiting Factor (GIF). This factor has been postulated by Krulich, Dhariwal and McCann (1968) and Krulich and McCann (1969) and its origin was thought to be outside the ME (Krulich, Quijada, and Ilner, 1971). Nakayama and his co-workers measured three ultrastructural parameters of the pituitary GH-synthesizing machinery: the surface area of the GHsynthesizing cell, the number of secretory granules per cell, and the mean diameter of the secretory granules. In previous studies, Nakayama and Nickerson (1973) used this approach to demonstrate that high circulatıng levels of $\mathrm{GH}-$ as in rats bearing the Furth MtT10 
tumor - caused significant reductions in $\mathrm{GH}$ cell granule number, surface area of the GH cell, and granule diameter. Application of this method to the study of GH cells in pituitaries from rats with $\mathrm{VMN}$ and DMN lesions demonstrated (Nakayama, Tseng and Bernardis, 1973; Nakayama, Bernardis and Tseng, 1974) that destruction of the VMN was followed by an increase of $30 \%$ above control levels in the number of secretory granules, mean diameter of the secretory granule and surface area of the $\mathrm{GH}$ synthesizing cell. This was taken as an indication of a state of prolonged inhibition of granule release and is compatible with the currently held view that GRF (Growth Hormone Releasing Factor) forming neurons are located in or near the VMN.

Destruction of the DMN, on the other hand, caused the opposite changes in $\mathrm{GH}$ cells: the number of secretory granules decreased rapidly after the hypothalamic operation and reached its lowest point 24 hours afterwards $-33 \%$ below control levels. The secretory granules reaccumulated slowly but were still $20 \%$ below control levels 19 days after the placement of the DMN lesions. The changes in the pituitaries of rats with DMN lesions were interpreted as indicating a state of hypersecretion, a rapid outpouring of secretory granules from pituitary stores. This is attributed to a lack of inhibition, possibly due to a lack of GIF (Growth Hormone Inhibitory Factor) whose formation site and/or storage locus must then be in the DMN or their immediate dorsal hypothalamic vicinity.

The data on changes in secretory granules and $\mathrm{GH}$ cells as provided by Nakayama and the plasma GH data following DMN lesions (Bernardis, 1973b) gain more meaning and significance when interpreted in the light of findings by the Critchlow group (Palka, Liebelt and Critchlow, 1971). Horizontal knife cuts through the hypothalamus that divided the VMN into ventral and dorsal halves were the most effective - among a number of types of cuts - in causing increased ponderal and linear growth and obesity. The authors interpreted their findings to indicate that ..." "neural elements responsible for growth reside in the VM region and that these elements receive inhibitory connections from other structures ..." The removal of these inhibitory connections by horizontal knife cuts as used by Palka, Liebelt and Critchlow (1971) are comparable to the DMN lesions in the Bernardis (1973b) and Nakayama (Nakayama, Tseng and Bernardis, 1973; Nakayama, Bernardis and Tseng, 1974) studies, inasmuch as both types of intervention interrupted connections between the dorsal and ventral circuits, i.e. between the dorsomedial area and the VMN. The lack of growth promotion, both in terms of weight and length, in all of the Bernardis studies is undoubtedly due to the profound and consistent hypophagia that characterizes the DMN rat (Bernardis, Box and Stevenson, 1963; Bernardis, 1970; Bernardis, 1972a, 1972b; Bernardis and Goldman, 1972; Bernardis, 1973; Bernardis Chlouverakis, Schnatz and Frohman, 1974).

Hypoglycemia has been recognized as the adequate stimulus for GH secretion (Roth, Glick, Yalow and Berson, 1963). The synthetic glucose analog, 2-deoxy-D-glucose (2DG), when given to animals and man, causes an enzymatic inhibition of glucose metabolism (Tower, 1958) that yields the same response as insulin administration (Houpt and Hance, 1971; Smith and Root, 1969). In an attempt to define the location in the hypothalamus of the chemoreceptors that might be activated by $2 D G$ or hypoglycemia, Himsworth, Carmel and Frantz (1972) have injected 2DG into various hypothalamic areas of macacca mulatta. While the injection sites alongside the midpart of the lateral VMN were effective in increasing plasma $\mathrm{GH}$ levels, injections into the DMN were consistently ineffective. Although these sites differ from those established by lesion (Bernardis and Frohman, 1967; Frohman and Bernardis, 1968) and stimulation studies (Frohman, Bernardis and Kant, 1968; Bernardis and Frohman,
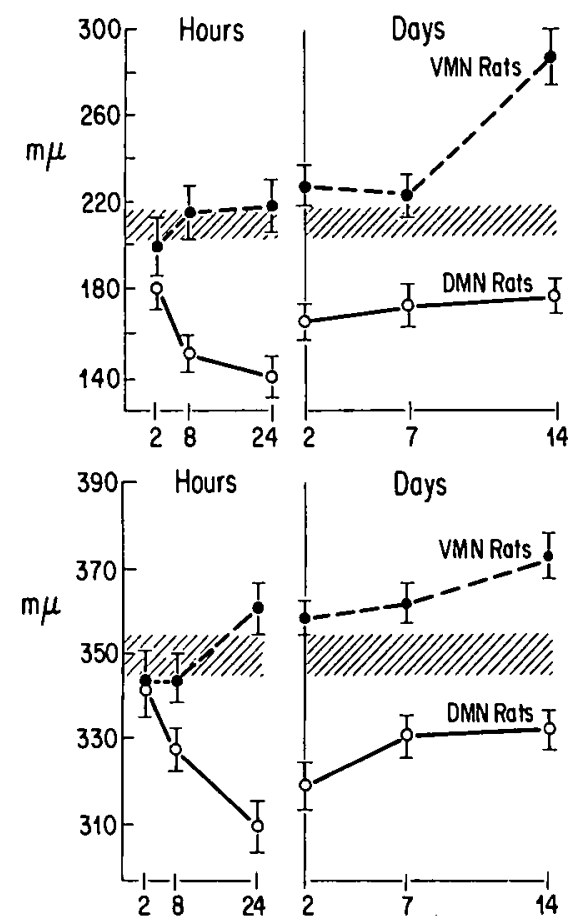

Figure 6 Upper Panel - Changes in the mean diameter of the largest secretory granule in each somatotroph of VMNand DMN-lesioned rats sacrificed 2,8, and 24 hours and 2,7, and 14 days after operation (Experiment 2). The crosshatched horizontal band shows the mean diameter of the largest granule and its standard error in the shamoperated control rats. The vertical lines in each point depict the standard error of the mean.

Lower Panel - Changes in the mean number of secretory granules per somatotroph cross section in the VMN- and DMN- lesioned rats sacrificed 2,8, and 24 hours and 2,7, and 14 days after the hypothalamic operation (Experiment 2). The crosshatched horizontal band shows the mean granule count and its standard error in the sham-operated controls. The vertical lines in each point show the standard error of the mean. Modified after Nakayama et al., 1974. 
1971; Martin, 1972; Tiovola and Gale, 1972, 1973), the authors indicate the fibers pass medially from the stimulated region to the VMN (Arees and Mayer, 1967; Nauta and Haymaker, 1969). The fact that the DMN area is unresponsive to hypoglycemia agrees with Bernardis' (1973b) findings that DMN lesions do not cause a decrease in plasma GH levels, and with the Bernardis and Frohman (1971) data that electrical stimulation of the DMN fails to bring about a rise in circulating $\mathrm{GH}$.

While adrenal function for years has been known to be influenced and controlled by a hypothalamic principle - Corticotrophin Releasing Factor (CRF, Saffran and Schally, 1955) that acts via pituitary $\mathrm{ACTH}$ and is found in ample amounts in the $\mathrm{ME}$, recent findings suggest the existence of an extra-pituitary control system as well. Following electrical stimulation of the ventromedial as well as the dorsomedial areas in the dog, an augmentation of adrenal blood flow and pressure was noted, the former not necessarily depending on the latter. While in nonhypophysectomized dogs there was no correlation between blood flow and adrenal corticoid release, such a correlation existed after hypophysectomy. The authors (Kovach, Moos, Kiltay and Desrius, 1970) interpret the coordination of this response in the light of a "dorsomedial sympathetic vasodilator relay" described by Folkow, Johansson and Oberg (1959) at which level the response is likely organized. It is also recalled that, with ACTH concentrations lower than the physiological minimum, cortisteroid response is changed in response to altered blood flow (Urquhart, 1965).

Some years ago, Szentagothai, Flerko, Mess and Halasz (1968) used changes of cell nucleus size in the various hypothalamic nuclei as an indicator of functional activity of the neurons. They derived their conclusions from experiments in which manipulation of the endocrine milieu was followed by profound alterations in cell nucleus size, reflecting neuronal activity in the hypothalamus. Subsequent studies by Ifft $(1962,1964)$ utililized changes in nucleolar size, rather than nuclear size, and related these changes to changes in various hypothalamic neurons. An increase in nucleolar size was attributed to an increase in neuronal activity. In his 1964 study, Ifft manipulated the endocrine system by extirpation of the pituitary, the thyroid, ovaries, adrenals and adrenal medulla. The nucleoli of the DMN did not show changes five days post hypophysectomy, but showed changes 60 days after hypophysectomy. The VMN nucleoli were decreased in size at five days, but not sixty days after hypophysectomy. Neither ovariectomy nor thyroidectomy affected VMN and DMN nucleolar size, and both adrenalectomy and adrenal demedullation increased nucleolar size in both VMN and DMN. The changes in the DMN in particular have to be interpreted in the light of alterations observed in other hypothalamic nuclei and it is particularly noteworthy that hypophysectomy, adrenalectomy and adrenal demedullation initiated changes in all of the 16 hypothalamic nuclei examined. Thus, the nucleolar size changes in the DMN appear to be affected in a generalized and nonspecific manner, but this might be expected from data on lesion and stimulation studies to be discussed subsequently. Unfortunately Ifft did not use insulin hypoglycemia, a specific and potent stimulus for the secretion of GH. This might have thrown some interesting light on the role of at least the VMN in GH dynamics. Hyperglycemia, on the other hand, might have set in motion a chain of events that could have implicated the DMN in the aforementioned role in GIF secretion.

The involvement of the DMN in thyroid function control has been examined by Vertes, Vertes and Kovacs (1965). Electrical stimulation of the nucleus in its anterior aspect was followed by a decrease in thyroidal $I^{\mathbf{1 3 1}}$ uptake. After adrenalectomy, however, stimulation in the DMN was followed by a greater uptake of $\mathrm{I}^{\mathbf{1 3 1}}$. While the authors concede that their data does not permit conclusions regarding the adrenalectomy-initiated reversal of iodine uptake, they hypothesize that it might be due to concomitant adreno-cortical stimulation, conceivably caused by increased ACTH or adrenocortical hormone secretion.

These findings have been confirmed by Martin and Reichlin (1972) who could not find a positive response in plasma Thyroid Stimulating Hormone (TSH) after DMN stimulation. They did find a positive response in one of their animals that had been stimulated longer than the other, non-responsive rats. The results of lesion studies are also in keeping with the above findings. Mess, Zanisi and Tima (1970) could not find changes in Thyrotropin Releasing Factor (TRF) seven days after the placement of DMN lesions.

While the DMN are undoubtedly involved in the secretion of Prolactin (LTH) as previously indicated, both the tonic and cyclic mechanisms controlling Luteinizing Hormone (LH) appear to be unrelated to DMN activity. This was shown by studies of the Sawyer group (Gallo, Johnson, Goldman, Whitmoyer and Sawyer, 1971) who demonstrated an increase in multiple unit activity (MUA) in the arcuate nuclei and the VMN following electrochemical stimulation of the ventral hippocampus. They also observed a depression of plasma LH 1 1 1/2 and 3 hours following stimulation. No increase in MUA was found in the DMN, the ME and the zona incerta.

\section{METABOLIC CONTROL}

The control of intermediary metabolism is generally thought to be executed by enzymes which have been activated - or induced - by hormones. The latter are either secreted by the pituitary directly, e.g. GH (Second Order Neuroendocrine System), Scharrer (1966), or require the action of a pituitary trophic hormone on a target gland that in turn releases the hormone, e.g. Thyroid Stimulating Hormone (TSH) and Thyroid Hormone (Third Order Neuroendocrine System) (Scharrer, 1966). 
Previous investigations in the central nervous system control of intermediary metabolism of carbohydrate and lipid have shown that in weanling rats with VMN lesions the epididymal fat pad oxidizes and incorporates glucose and palmitate with great avidity, while oxidation of the latter metabolite is decreased (Goldman, Bernardis, Frohman and Schnatz, 1968; Goldman, Schnatz, Bernardis and Frohman, 1970; Goldman, Schnatz, Bernardis and Frohman, 1971). The importance of this finding is emphasized by the fact that the above changes are evident in hypophysectomized (Goldman, Schnatz, Bernardis and Frohman, 1970) and streptozotocin-diabetic rats (Goldman, Schnatz, Bernardis and Frohman, 1972). To clarify and define the hypothalamic site involved in the initiation of this phenomenon, the studies were extended to the weanling rat with DMN lesions (Bernardis and Goldman, 1972). It should be recalled that the latter hypothalamic model shows normal plasma glucose, insulin, growth hormone, triglyceride and cholesterol levels (see above).

Epididymal fat pads from rats with DMN lesions placed shortly after weaning showed significantly lower incorporation of palmitate into phospholipid and diglyceride in comparison with ad libitum-fed, sham-operated controls, whereas incorporation into triglyceride was unaltered. It is of interest to note that these parameters are normal in the fat tissue of controls that were fed the same amount of food eaten by the (hypophagic) DMN-lesioned rats.

The data for the diaphragm are quite different. The DMN-operated rats incorporated significantly less glucose into total lipid and glycogen, while in comparison with pair-fed controls the DMN rats showed no significant alterations when compared with ad libitum-fed controls. The authors noted that ... "striking somatic changes are not matched by similarly striking changes in the intermediary metabolism of glucose and palmitate." They hypothesized that the DMN rat ..." within the framework of its somaticphysiological potential, is better equipped to exist with smaller amounts of substrate for its metabolism than is the calorierestricted sham-operated control." This more efficient adaptation to reduced calories is speculated to be due to a "resetting" of central autonomic mechanisms which need not necessarily exert their effect via adenohypophyseal secretions (Bernardis and Goldman, 1972).

It has been noted that lesions in the VMN of the mature rat are followed by a profound increase in body weight (Brobeck, Tepperman and Long, 1943; Hetherington and Ranson, 1942; Smith, 1927), this being due to increased lipogenesis. It was long thought that the latter was simply due to the hyperphagia which characterizes the mature VMN rat. Subsequent work, however, has indicated that mature rats with VMN lesions become hyper-insulinemic (Hales and Kennedy, 1964) and insulin is well known to be a potent lipogenic hormone. Subsequent work has also shown that both obesity and hyperinsulinemia develop in tube-fed hypophysectomized rats with VMN lesions, indicating that the endocrine pancreas is involved in hypothalamic obesity and demonstrating that hyperinsulinemia can develop in the absence of hyperphagia and pituitary hormones (Han and Frohman, 1970).

The weanling VMN rat, on the other hand, does not gain more weight than its sham-operated control but is hyperinsulinemic and normoglycemic and normophagic and has a higher carcass fat content with lower lean body mass and water (Bernardis and Frohman, 1967, Bernardis, 1970, Bernardis and Frohman, 1970). While it was first thought (Frohman and Bernardis, 1968) that the increased lipogenesis was due to the high insulin levels hyperplagia per se had to be excluded-it was subsequently demonstrated that obseity and the above metabolic changes occur in the absence of pituitary (Goldman, Schnatz, Bernardis and Frohman, 1970) and an endocrine pancreas
(Goldman, Schnatz, Bernardis and Frohman, 1972). Studies in the DMN rat, on the other hand, have shown that body composition is normal (Bernardis, 1970), and that hypophagia and subnormal body weight gains co-exist in the face of normoinsulinemia and normoglycemia (Bernardis and Frohman, 1971). Evidently, the destruction of two neuronal assemblies so closely appositioned in the hypothalamus brings about entirely different metabolic responses. The question as to why the weanling DMN rat has a normal carcass fat content in view of the reduced food intake is difficult to interpret. Possibly, the DMN rat preserves energy by reducing its activity which thus might account for a normal fat storage in view of reduced food intake (Bernardis, 1972a, 1972b).

The foregoing review has attempted to show that a hypothalamic area, removed from the median eminence and thus the portal circulation, exerts a profound influence on both adenohypophyseal and extrapituitary control mechanisms of homeostasis.

\section{CONCLUDING REMARKS}

The data of this review indicate that an area of the hypothalamus that up to now has received relatively little attention - the Dorsomedial Hypothalamic Nuclei (DMN) - exerts profound influences on a wide spectrum of homeostatic mechanisms. It is involved in extrapituitary-autonomic control systems: food and water intake, diurnal cyclicity, spontaneous activity, metabolism in terms of the fate of both intermediates and circulating substrates, and adrenal function by affecting adrenal blood flow. It is also involved in hypothalamo-pituitary relationships of neuroendocrine nature: control or modulation of Luteotrophic Hormone (LTH) and growth and Growth Hormone possibly by modulating Growth Hormone Inhibiting Factor (GIF). Most of the parameters measured show reponses of different direction and magnitude when compared with parameters obtained from Ventromedial Hypothalamic 
Nucleus (VMN) - manipulated rats, at least in weanling animals. Although the data on intranuclear and intrahypothalamic fiber connections unequivocally point to an extensive degree of interdigitation of the DMN circuits with these or other hypothalamic areas, particularly the VMN, the endocrine and metabolic data indicate a great deal of localization-specificity. The latter type of data therefore suggest that the currently fashionable aversion to the "center concept" of hypothalamic control localization may have to be revised, at least in terms of functional specificity. Obviously, two so closely appositioned neuronal assemblies subserve entirely different, if not opposite homeostatic functions.

\section{SUMMARY}

(Continued from page 45)

duced spontaneous activity (running wheel), but this reduced activity is not accompanied by increased weight gain and accretion of adipose tissue, the latter being consistently observed in the $V M N$ rat. Rather, carcass fat remains normal in the DMN rat and carcass protein is either normal or slightly increased. Many of the aforementioned changes in weanling rats with DMN lesions, however, are not matched by similar alterations in the intermediary metabolism of carbohydrate and lipid. Possibly this is due to a "resetting" of a central autonomic control system that makes it possible for the DMN rat to adapt more efficiently to a reduced influx of substrate, i.e. the consistent hypophagia. From a review of the literature it appears that the DMN and their circuitry are involved in only a few neuroendocrine, i.e. hypothalamohypophyseal control mechanisms. Both lesion and cervical stimulation experiments suggest an involvement of the DMN in the control of LTH. Circumstantial evidence points to the DMN as a possible formation and/or storage site of growth hormone inhibiting factor (GIF). Although DMN rats show reduced ponderal and linear growth, they have been found to have normal or elevated plasma growth hormone (GH) levels. Both lesion and stimulation studies have yielded the impression that the DMN is not involved in thyroid, i.e., thyrotropin stimulating hormone releasing factor (TSHRF) control. Electrical stimulation of the DMN has been reported to result in a positive correlation between adrenal blood flow and adrenal corticoid release in hypophysectomized dogs. This has been interpreted as a coordinated response at the level of a "dorsomedial sympathetic vasodilator relay" rather than a "true", neuroendocrine effect via corticotropin releasing factor $(C R F)$. Experiments that failed to demonstrate a relationship between the DMN and the tonic and cyclic control of luteinizing hormone releasing factor (LHRF) are discussed. The data reviewed indicate the existence in the dorsomedial hypothalamus of an area that exerts a profound influence on many aspects of neurovisceral and some neuroendocrine control systems.

\section{REFERENCES}

ANAND, B. L. and BROBECK, J. R. (1951): Hypothalamic control of food intake in rats and cats. Yale Journal of Biology and Medicine 24:123-140.

ANDEN, N. E., DAHLSTROM, A., FUXE, K., and LARSSON, K. (1965): Further evidence for the presence of nigroneostriatal dopamine neurons in the rat. American Journal of Anatomy 116:329-333.

ANDEN, N. E., DAHLSTRÖM, A., FUXE, K., LARSSON, K., OLSON, L. and UNGERSTEDT, U. (1966): Ascending monoamine neurons to the telencephalon and diencephalon. Acta Physiologica Scandinavica 67:313-326.

AKERT, K. (1961): Diencephalon: In: Electrical Stimulation of the Brain, Sheer, D.E., ed. Austin Hogg Foundation for Mental Health, University of Texas Press, pp. 288-310.

AREES, E. A. and MAYER, J. (1967): Anatomical connections between medial and lateral regions of the hypothalamus concerned with food intake. Science 157: 1574-1575.

ARIENS KAPPERS, C. U., HUBER, G. C., and CROSBY, E. C. (1960): The comparative anatomy of the nervous system of vertebrates, including man. Hafner Publishing Company. (Originally published in 1936 in two volumes).

BAN, T. (1964): The hypothalamus, especially on its fiber connections, and the septo-preoptic-hypothalamic system. Medical Journal of Osaka University, 15, 1-83.

BERNARDIS, L. L., BOX, B. M. and STEVENSON, J. A. F. (1963): Growth following hypothalamic lesions in the weanling rat. Endocrinology 72:684-692.

BERNARDIS, L. L. and FROHMAN, L. A. (1967): Plasma and pituitary growth hormone levels in rats with hypothalamic lesions. Endocrine Society Annual Meeting, p. 86.

BERNARDIS, L. L. (1970): Participation of the dorosmedial hypothalamic nucleus in the "feeding center" and water intake circuitry of the weanling rat. Journal of Neuro-Visceral Relations 31:387-398.
BERNARDIS, L. L. and FROHMAN, L. A. (1970): Effect of lesion size in the ventromedial hypothalamus on growth hormone and insulin levels in the weanling rat. Neuroendocrinology 6:319-328.

BERNARDIS, L. L. and FROHMAN, L. A. (1971): Plasma growth hormone responses to electrical stimulation of the hypothalamus in the rat. Neuroendocrinology 7:193-201.

BERNARDIS, L. L., and SCHNATZ, J. D. (1970): Localization in the ventromedial hypothalamus of an area affecting plasma lipid levels. Journal of Neuro-Visceral Relations 32:522-537.

BERNARDIS, L. L. (1972a): Hypophagia, hypodipsia and hypoactivity following electrolytic lesions in the dorsomedial hypothalamic nuclei of mature rats of both sexes. Journal of Neural Transmission 33: $1-10$.

BERNARDIS, L. L. (1972b): Hypophagia, hypodipsia and hypoactivity following dorsomedial hypothalamic lesions. Physiology and Behavior 8:1151-1164.

BERNARDIS, L. L. (1972c): Hypoactivity as a possible contributing cause of obesity in the weanling rat ventromedial syndrome. Canadian Journal of Physiology and Pharmacology 50:370-372.

BERNARDIS, L. L. and GOLDMAN, J. K. (1972): Growth and Metabolic changes in weanling rats with lesions in the dorsomedial hypothalamic nuclei. Experimental Brain Research 15:424-429.

BERNARDIS, L. L. (1973): Disruption of diumal feeding and weight gain cycles in weanling rats by ventromedial and dorsomedial hypothalamic lesions. Physiology and Behavior 10:855-861.

BERNARDIS, L. L. (1973): Normal plasma growth hormone levels in growth-retarded weanling rats with dorsomedial hypothalamic lesions. Experimental Brain Research 18:374-382.

BERNARDIS, L. L., CHLOUVERAKIS, C., SCHNATZ, J. D., FROHMAN, L. A. (1974): Effect of dorsomedial hypothalamic lesions before and after placement of obesity-producing ventromedial hypothalamis lesions in the weanling male rat. Brain Research 69:67-75.

BROBECK, J. R., TEPPERMAN, J. and LONG, C. N. H. (1943): Experimental hypothalamic hyperphagia in the albino rat. Yale Journal of Biology and Medicine 15:831-853.

BROOKS, C. M. (1946): The relative importance of changes in activity in the development of experimentally produced obesity in the rat. American Journal of Physiology 147:708-716.

BRÜGGER, M. (1943): Fresstrieb als hypothalamisches Symptom, Helvetica Physiologica Acta 1:183-198.

CAMPBELL, B. A. and SHEFFIELD, F. D. (1953): Relation of random activity to food deprivation. Journal of Comparative Physiological Pharmacology 46:320-322. 
CHI, C. C. (1970): Afferent connections to the ventromedial nucleus of the hypothalamus in the rat. Brain Research 17:439-445.

CHRIST, J. F. (1969): Derivation of the boundaries of the hypothalamus with atlas of hypothalamic grisei. In: The Hypothalamus. W. Haymaker, E. Anderson and W. J. H. Nauta, eds. Charles C. Thomas, Springfield, Illinois.

DAHLSTROM, A. and FUXE, K. (1964): Evidence for the existence of monoaminecontaining neurons in the central nervous system. I. Demonstration of monoamines in the cell bodies of brain stem neurons. Acta Physiologica Scandinavica 62, Supplement 232, $1-55$.

DeGROOT, J. (1967): Organization of hypothalamic feeding mechanisms. Handbook of Physiology, Chapter Volume I, 239-247.

DELGADO, J. M. R. and ANAND, B. K. (1953): Increase of food intake induced by electrical stimulation of the lateral hypothalamus. American Journal of Physiology 172:162-168.

EAGER, R. P., CHI, C. C., and WOLF, G. (1971): Lateral hypothalamic projections to the hypothalamic ventromedial nucleus in the albino rat: demonstration by means of a simplified ammoniacal silver degeneration method. Brain Research 29:128-132.

EVERETT, J. W. and QUINN, D. L. (1966): Differential hypothalamic mechanisms inciting ovulation and pseudopregnancy in the rat. Endocrinology 78:141-150.

FIELD, P. M. (1972): A quantitative ultrasIructural analysis of the distribution of amygdaloid fibers in the preoptic area and the ventromedial hypothalamic nucleus. Exp. Brain Res. 14:527-538.

FOLKOW, B., JOHANSSON, B., OBERG, B. (1959): A hypothalamic structure with a marked inhibitory effect on tonic sympathetic activity. Acta Physiologica Scandinavica 47:262-270.

FROHMAN, L. A. and BERNARDIS, L. L. (1968): Growth hormone and insulin levels in weanling rats with ventromedial hypothalamic lesions. Endocrinology 82:1125-1132.

FROHMAN, L. A., BERNARDIS, L. L. and KANT, K. J. (1968): Hypothalamic stimulation of growth hormone secretion. Science 162:480-582.

FUXE, K. (1965): Evidence for the existence of monoamine-containing neurons in the central nervous system. IV. Distribution of monoamine nerve terminals in the central nervous system. Acta Physiologica Scandinavica 64:Suppl. 247, 37-85.

GALLO, R. V., JOHNSON, J. H., GOLDMAN, B. D., WHITMOYER, D.I. and SAWYER, C. H. (1971): Effects of electrochemical stimulation of the ventral hippocampus on hypothalamic electrical activity and pituitary gonadoptropin secretion in female rats. Endocrinology 89:704-713.

GLADFELTER, W. E., and BROBECK, J. R. (1962): Decreased spontaneous motor activity in the rat induced by hypothalamic lesions. American Journal of Physiology 203:811-817.

GLOOR, P. (1956): Telencephalic influences upon the hypothalamus. HypothalamoHypophyseal Interrelationships. W. S. Fields, R. Guillemin and C. A. Carton, eds. 74-114. Springfield, Illinois, C. C. Thomas. GOLDMAN, J. K., BERNARDIS, L. L., FROHMAN, L. A. and SCHNATZ, J. D. (1968): Glucose and fatty acid utilization by tissues of weanling rats with ventromedial hypothalamic lesions. Diabetes 17:301.

GOLDMAN, J. K., SCHNATZ, J. D., BERNARDIS, L. L. and FROHMAN, L. A. (1970): Adipose tissue metabolism of weanling rats after destruction of the ventromedial hypothalamic nuclei: effect of hypophysectomy and growth hormone. Metabolism 945-1005.

GOLDMAN, J. K., SCHNATZ, J. D., BERNARDIS, L. L. and FROHMAN, L. A. (1971): Effect of pre-existing streptozotocin diabetes on changes associated with destruction of the ventromedial hypothalamic nuclei. American Diabetes Association Annual Meeting, San Francisco.

GOLDMAN J.K., SCHNATZ, J. D., BERNARDIS, L. L., and FROHMAN, L. A. (1972): Effects of ventromedial hypothalamic destruction in rats with preexisting streptozotocin-induced diabetes. Metabolism 21:132-136.

GROSSMAN, S. P. (1962): Direct adrenergic and cholinergic stimulation of hypothalamic mechanisms. American Journal of Physiology 202:872-882.

GUILLERY, R. W. (1957): Degeneration on the hypothalamic connections of the albino rat. Journal of Anatomy 91:91-115.

GURDJIAN, E. S. (1927): The diencephalon of the albino rat. Journal of Comparative Neurology 43:1-115.

HALASZ, B., PUPP, D. and UHLARIK, S. (1962): Hypophysiotrophic area in the hypothalamus. Journal of Endocrinology 25:147-154.

HALES, C. N. and KENNEDY, G. C. (1964): Plasma glucose, non-esterified fatty acids and insulin concentration in hypothalamic-hyperphagic rats. Biochemical Journal 90:620-624.

HAN, P. W. and FROHMAN, L. A. (1970): Hyperinsulinemia in tube-fed and hypophysectomized rats bearing hypothalamic lesions. American Journal of Physiology 219:1632-1636.

HEIMER, L., and NAUTA, W. J. M. (1969): The hypothalamic distribution of the stria terminalis in the rat. Brain Research 13:284-297.

HETHERINGTON, A. W. and RANSON, S. W. (1942): The relation of various hypothalamic lesions to adiposity in the rat. Journal of Comparative Neurology 76:475-499.

HETHERINGTON, A. W and RANSON, S. W. (1942): The spontaneous activity and food intake of rats with hypothalamic le- sions. American Journal of Physiology 137:609-617.

HILD, W. and ZETLER, G. (1953): Über die Funktion des Neurosekrets im Zwischenhirn-Neurohypophysensystem als Trägersybstanz für Vasopressin, Adiuretin and Lxytozin. Zeitschrift der gesamten experimentellen Medizin 120:236-243.

HIMSWORTH, R. L., CARMEL, P. W. and FRANTZ, A. G. (1972): The location of the chemoreceptor controlling growth hormone secretion during hypoglycemia in primates. Endocrinology 91:217-226.

HORSTMANN, E. (1954): Die Faserglia des Selachiergehirns. Zeitschrift fur Zellforschung und mikroskopische anatomie 39:588-617.

HOUPT, T. R. and HANCE, H. E. (1971): Stimulation of food intake in the rabbit and rat by inhibition of glucose metabolism with 2-Deoxy-D-Glucose, Journal of Comparative Physiology 63:395-400.

IFFT, J. D. (1962): Evidence of gonadotropic activity of the hypothalamic arcuate nucleus in the female rate. Anatomical Record 142: 108 .

IFFT, J. D. (1964): The effect of endocrine gland extirpations on the size of nuclei in rat hypothalamic neurons. Anatomical Record 148:599-604.

JOHNSON, T. N. (1965): An experimental study of the fornix and hypothalamotegmental tracts in the cat. Journal of Comparative Neurology 125:29-40.

JONSSON, G., FUXE, F., and HÖKFELT T. (1972): On the catecholamine innervation of the hypothalamus, with special reference to the median eminence. Brain Research 40:271-281.

KAWAKAMI, M. and IBUKI, T. (1972): Multiple unit activity in the brain correlated with induction and maintenance of pseudopregnancy in rats. Neuroendocrinology 9:2-19.

KNIGGE, K. M., SCOTT, D. E., WEINDL, T., KARGER, W. G. (1972) Eds: BrainEndocrine Interaction. Median Eminence: Structure and Function.

KOVACH, A. G. B., MONOS, E., KOLTAY, E., and DESRIUS, A. (1970): Effect of hypothalamic stimulation on adrenal blood flow and glycocorticoid release prior to and after acute hypophysectomy. Acta Physiologica Academiae Scientiarum Hungariae 38:205-215.

KRIEG, W. J. S. (1932): The hypothalamus of the albino rat. Journal of Comparative Neurology 55:19-89.

KRULICH, L., DHARIWAL, A. P. S., McCANN, S. M. (1968): Stimulatory and inhibitory effects of purified hypothalamic extracts on growth hormone release from rat pituitary in vitro. Endocrinology 82:783-790.

KRULICH, L. and McCANN, S. M. (1969): Effect of $\mathrm{GH}$ releasing factor and $\mathrm{GH}$ inhibiting factor on the release and concentration of $\mathrm{GH}$ on pituitaries incubated in vitro. Endocrinology 85:319-324. 
KRULICH, L., QUIJADA, M., ILLNER, P. (1971): Localization of prolactin-inhibiting factor (PIF), P-releasing factor (PRF), growth hormone-RF (GRF) and GIF activities in the hypothalamus of the rat. Endocrinology Society Annual Meeting, Abstract No. 2 (A-83).

LARSSON, S. (1954): On the hypothalamic organization of the nervous mechanisms regulating food intake. Acta Physiologica Scandinavica 32 (Supplement 115): 7-61.

MARTIN, J. B. (1972): Plasma growth hormone $(\mathrm{GH})$ response to hypothalamic or extrahypothalamic electrical stimulation. Endocrinology 91:107-115.

MARTIN, J. B. and REICHLIN, S. (1972): Plasma thyrotropin (TSH) response to hypothalamic electrical stimulation and to injection of synthetic thyrotropin releasing hormone (TRH). Endocrinology 90: 1079-1085.

The Hypothalamus. Eds. L. MARTINI, M. MOTTA, F. FRASCHINI. Academic Press 1970.

MATANO, S., SAKAI, A., BAN, T. (1969): Dendritic arborization of the hypothalamus in the mouse. Medical Journal of Osaka University 20:1-6.

MAYER, J. and AREES, E. A. (1968): Ventromedial glucoreceptor system. Federation Proceedings 27:1345-1353.

MESS, B., FRASCHINI, F., MOTTA, M., and MARTINI, L. (1967): The topography of the neurons synthesizing the hypothalamic releasing factors. In: Hormonal Steroids, L. Martini, F. Fraschini and M. Motta, eds., Excerpta Medica, Amsterdam 1004-1013.

MESS, B., ZANISI, M., and TIMA, L. (1970): Site of production of releasing and inhibiting factors. In: The Hypothalamus, eds. L. Martini, M. Motta, F. Fraschini. Academic Press 239-276.

MILLHOUSE, O. E. (1969): A Golgi study of the descending medial forebrain bundle. Brain Research 15:341-363.

MILLHOUSE, O. E. (1971): A Golgi study of third ventricle tanycytes in the adult rodent brain. Zeitschrift für Zellforschung und mikroskopische Anatomie 121:1-13.

MILLHOUSE, O. E. (1973a): The organization of the ventromedial hypothalamic nucleus. Brain Research 55:71-87.

MILLHOUSE, E. O. (1973b): Certain ventromedial hypothalamic afferents. Brain Research 55:89-105.

MONTEMURRO, D. G. and STEVENSON, J. W. F. (1957): Adipsia produced by hypothalamic lesions in the rat. Canadian Journal of Biochemistry and Physiology 35:31-37.

MORRISON, S. D. (1968): The relationship of energy expenditure and spontaneous activity to the asphagia of rats with lesions in the lateral hypothalamus. Journal of Physiology (London) 197:325-343.

NAKAYAMA, I. and NICKERSON, P. $\Lambda$. (1973): Suppression of anterior pituitary in rats bearing a transplantable growth hormone and prolactin-secreting tumor (Mt T-W10). Endocrinology 92:516-524.
NAKAYAMA, I., TSENG, M. T. and BERNARDIS, L. L. (1973): Ultrastructural evidence for possible localization of growth hormone inhibiting factor (GIF) in dorsomedial hypothalamus. Federation Proceedings 32:265 (Paper 293), Atlantic City.

NAKAYAMA, I., BERNARDIS, L. L. and TSENG, M. T. (1974): Ultrastructural studies of adenohypophyseal somatotrophs in weanling rats with ventromedial and dorsomedial hypothalamic lesions. Laboratory Investigation 30:119-129.

NALBANDOV, A. (1963): Ed. Advances in Neuroendocrinology, University of Illinois Press, Urbana.

NAUTA, W. J. and HAYMAKER, W. (1969): Hypothalamic nuclei and fiber connections. In: The Hypothalamus, Haymaker, W., Anderson, E. and Nauta W. J. H. Eds. pp. 136-209, Charles C. Thomas, Springfield

NIKTOVITCH-Winer, M. B. (1960): The influence of the hypothalamus on luteotrophin secretion in the rat. Memoirs of the Society for Endocrinology, 9:70-72.

OLIVECRONA, H. (1957): Paraventricular nuclei and pituitary gland. Acta Physiologica Scandinavica 40, Supplement 136, 1-178.

PALKA, Y., LIEBELT, N. A. and CRITCHLOW, V. (1971): Obesity and increased growth following partial or complete isolation of ventromedial hypothalamus. Physiology and Behavior 7:187-194.

PETROVICKY, P. (1967): Hypothalamoreticular connections in the rat. Acta Universitatis Carolinae Medica 13:385-396.

RAISMAN, G. (1970): An evaluation of the basic pattern of connections between the limbic system and the hypothalamus. American Journal of Anatomy 129, 197-202.

REICHLIN, S. (1961): Growth hormone (GH) content of pituitaries in rats with hypothalamic lesions. Endocrinology 69:225-231.

RICHTER, C. P. (1927): Animal behavior and internal drives. Quarterly Review of Biology 2:307-343.

RICHTER, C. P. (1952): The effect of domestication on the steroids of animals and man. Ciba Foundation Colloq. Endocrinology III: 89-111, Blakiston, N.Y.

RICHTER, C. P. (1967): Sleep and activity: their relation to the 24-hour clock. In: Sleep and Altered States of Consciousness. S.S. Key et al., Eds. Williams and Wilkins, Baltimore.

RODGERS, W. L., EPSTEIN, A. N. and TEITELBAUM, P. (1965): Lateral hypothalamic aphagia: motor failure or motivational deficit? American Journal of Physiology 208:334-342.

ROTH, J., GLICK, S. M., YALOW, R.S and BERSON, S.A. (1963); Hypoglycemia: a potent stimulus to secretion of growth hormone. Science 140: 987-988.

SAFFRAN, M. and SCHALLY, A. V. (1955): Release of corticotrophin by anterior pituitary tissue in vitro. Canadian
Journal of Biochemistry and Physiology 33:408-415.

SCHARRER, E. (1966): Principles of Neuroendocrine Integration. In: Endocrines and the Central Nervous System. Assoc. Res. Nerv. Ment. Dis. Vol. 43, Chap. I Baltimore, The Williams and Wilkins Company.

SCREMIN, O. U. (1970): The Vascular anatomy of the rat's hypothalamus in stereotaxic coordinates. Journal of Comparative Neurology 139:31-52.

SHOWERS, M. J. (1958): Correlation of medial thalamic nuclear activity with cortical and subcortical neuronal ares. Journal of Comparative Neurology 109:261-302.

SHUTE, C. C. C. and LEWIS, P. R. (1963): Cholinesterase-containing systems of the brain of the rat. Nature (London) 199:1160-1164.

SLONAKER, J. R. (1925): The effect of copulation, pregnancy, pseudopregnancy and lactation on the voluntary activity and food consumption of the albino rat. American Journal of Physiology 71:362-394.

SMIALOWSKI, A. (1973): Lateral hypothalamic nuclei in the macaque (Macaca mulatta) brain: myeloarchitectonics. Acta Anatomy 85:332-341.

SMITH, P. E. (1927): The disabilities caused by hypophysectomy and their repair. Journal of the American Medical Association 88: 158-161.

SMITH, G. P. and ROOT, A. W. (1969): Effect of feeding on hormonal responses to 2-Deoxy-D-glucose in conscious monkeys. Endocrinology 84:963-966.

SMITH, G. C. and FINK, G. (1972): Experimental studies on the origin of monoaminecontaining fibers in the hypothalamohypophysical complex of the rat. Brain Research 43:37-51.

STEVENSON, J. A. F. and RIXON, R. H. (1957): Environmental temperature and deprivation of food and water on the spontaneous activity of rats. Yale Joumal of Biology and Medicine 29:575-584.

SUTIN, J. (1966): The periventricular stratum of the hypothalamus. International Review of Neurobiology 9:263-300.

SZENTAGOTHAI, J., FLERKO, B., MESS, B., and HALASZ, B. (1963): Hypothalamic Control of the Anterior Pituitary. Akademiai Kiado, Budapest. 1968 (third edition).

TEITELBAUM, P. and EPSTEIN, A. N. (1962): The lateral hypothalamic syndrome: recovery of feeding and drinking after lateral hypothalamic lesions. Psychological Review 69:74-90.

TOIVOLA, P. T. K., and GALE, C. C. (1972): Stimulation of growth hormone by microinjection of norepinephrine into hypothalamus of baboon. Endocrinology 90:895-902.

TOIVOLA, P. T. K. and GALE, C. C. (1973): Norepinephrine and dopamine microinjection into the hypothalamus of baboons: effect on growth hormone secretion. Federation Proceedings 32:265 (Paper No. 292). 
TOWER, D. B. (1958): The effects of 2-deoxy-D-glucose on metabolism of slices of cerebral cortex incubated in vitro. Journal of Neurochemistry 3:185-205.

URQUHART, J. (1965): Adrenal blood flow and the adrenocortical response to corticotrophin. American Journal of Physiology 209:1162-1168.
VALENSTEIN, E. S., COX, V. C. and KAKOLEWSKI, J. W. (1969): Sex differences in hyperphagia and body weight following hypothalamic damage. Annals of the New York Academy of Sciences 157: $1030-1048$.

VERTES, M., VERTES, Z., and KOVACS, S. (1965): Effect of hypothalamic stimula- tion on pituitary-thyroid function. Acta Physiologica AcademiaeScientiarum Hungaricae 27:229-235.

WALD, G. and JACKSON, B. (1944): Activity and nutritional deprivation. Proceedings of the National Academy of Sciences, U.S.A. 30:255-263. 